\title{
2002018
}

\section{Optimization of the Shot Peening Parameters}

\author{
Franck Petit-Renaud \\ USF Impact Finishers (Shot Peening Division) and USF Vacu-Blast International, Slough, UK
}

\section{$1 \quad$ Abstract}

The shot peening process is a complicated mechanism in materials science, which is still not fully understood. Despite a long history and a large number of investigations into the process it is still characterized by many areas of uncertainty.

Notwithstanding this situation the aerospace and automotive industries have for years considered shot peening as a state-of-the-art process for the surface improvement, forming and life improvement of many parts.

The work described in this paper is a study of the effect of a range of process parameters on the residual stress profiles produced by shot peening coupons of case carburized 17CrNiMo6 steel.

The peening process utilized for the research was undertaken using a commercial shot-peening unit supplied by USF Vacu-Blast Limited using $0.6 \mathrm{~mm}$ diameter shot. The process parameters investigated included air pressure, the mass flow, the impact angle, the distance between the nozzle and the specimen, the exposure time and the nozzle size. Using Minitab v12 software regression analyses were performed on the results obtained from the statistically designed experiments. It was found that the most significant parameters were air pressure, the mass flow, the impact angle and the exposure time. Further important and significant interactions were also detected between exposure time and air pressure; nozzle size and mass flow; air pressure and impact angle; nozzle size and air pressure.

\section{Introduction}

The study of the different parameters involved in shot peening applications is important in order to have better understanding and control of such process. The significance and influence of these parameters are not yet clearly established and most of the knowledge is based on practical experience rather than detailed research. There are only limited methods of assessing the results obtained from peening (e.g. Almen strips) and prediction of final properties is not possible yet.

The investigation presented in this paper was aimed at designing and carrying out experimental procedures in order to understand the effects of shot peening on components by analyzing the changes occurred during the process. Therefore, determining the parameters involved to carry out the process and measuring residual stress in peened specimen were the two objectives of the investigation.

Being able to relate the shot peening parameters directly to the result produced by the process would indeed be of great advantage as it could lead to a better and more accurate control of shot peening. It would mean predicting the result induced by peening a component and increase the reliability of such process [16][17][18]. 
It was not intended to generalize the whole process but, focusing on what seemed to be the heart of shot peening and limiting the investigation to one type of material. Measuring the change in residual stress within the specimens used was thought to be the most interesting and useful way of understanding the process.

A statistical approach to the problem was used to design all the experiments and specific tools for the analysis of the results considered.

It is believed that this investigation was one of the most complete in terms of relating different set of parameters to different responses; the considerable number of residual stress measurements carried out could be used as a good basis for an even wider research program into the process, aiming at building software and database, dedicated to produce known effects on components and increasing the reliability of the shot peening process.

\section{Process Effects}

The immediate effect of bombarding high velocity shots onto a metallic target is the creation of a thin layer of high magnitude compressive residual stress at or near the metal surface, which is balanced by a small tensile stress in the deeper core (Figure 1).

The magnitude of this compressive residual stress is a function of the mechanical properties of the target material and may reach values as high as 50 to $60 \%$ of the material's ultimate tensile strength [1][3].

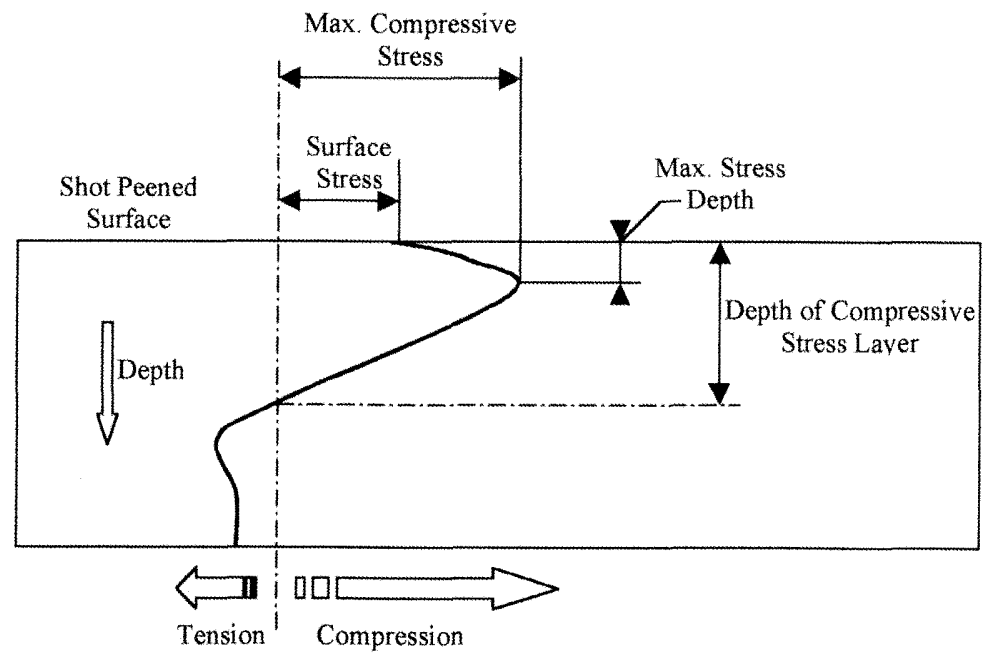

Figure 1: Effects of shot peening

Its depth is largely dependent on the peening intensity and the relative hardness of the impinging shot and target material. For a relatively soft target material (230-300 HV), it is feasible to produce a compressive layer of 800 to $1000 \mu \mathrm{m}$ deep, whilst for a harder material $(700 \mathrm{HV})$, it can be difficult to produce a compressive layer of much more than 200 to $250 \mu \mathrm{m}$ [1][2]. 
The introduction of this compressive residual stress at the metal surface layer brings one major benefit: it reduces and can negate any residual or subsequently imposed tensile stress at the metal surface [9][11]. As it is well known, most fatigue failures and stress corrosion failures normally start at or near the surface stressed in tension [2][3]. Therefore, by reducing the net tensile stresses at and near the surface of the component, fatigue crack initiation and stress corrosion can be delayed, improving the fatigue life of the component treated [10][12][13].

If the resultant surface stress can be made compressive enough, cracks could virtually be prevented from opening up at the component surface resulting in a much enhanced fatigue life [3][5][6]. This is generally true for shot-peened components subjected to low stress amplitudes.

\section{$4 \quad$ Process Parameters}

The shot peening process has to be a precisely controlled and repeatable process for optimum benefit. To achieve this, all its process variables must be identified and controlled [7]. There are many fundamental parameters affecting the shot peening process.

The most common are as follows:

- Shot density;

- Hardness and size of the shot;

- Nozzle characteristics (diameter, deflection angle, length);

- Air pressure:

- Impact angle;

- Distance from nozzle to work-piece;

- Exposure time, number of passes;

- Linear and rotational speed of work-piece relative to nozzle.

To specify all these variables every shot-peening job would require time consuming investigations and industrially impractical procedures. To overcome this problem, J. O. Almen [4][8] introduced the concept of peening intensity measurement based on curvature induced in a thin test strip, by which most of the previously listed process parameters can automatically be incorporated into one process variable called the Almen peening intensity [2][3][4]. With peening intensity known, one has only to define the shot type and size and peening coverage desired to fully define the peening process.

As experience and various studies have demonstrated the improvements induced by the peening process, it is widely used to enhance the life of components operating in highly stressed environment and other critical parts such as in Formula 1 motor racing, aero engines and aero structures [14][15]. Despite important progress in understanding the process, some areas are not totally mastered yet and difficulties are still hard to avoid. Being able to predict the effect of the process in set conditions is indeed the key to gain complete control over the process and to make it much more reliable. 


\section{$5 \quad$ The Test Specimens}

The dimensions of the test specimen are $10 * 10 * 100 \mathrm{~mm}$. The material used was the steel 17CrNiMo6, chosen because of its interest for gear manufacturing. The manufactured bars were carburized, quenched, tempered and lightly ground before being peened to maximize the effects of the process. At the end of heat treatment, the bars were expected to exhibit a Vickers surface hardness of approximately $700 \mathrm{kgf.mm} \mathrm{mm}^{-2}$, which is typical of many case hardened gears.

In order to limit the number of specimens to be manufactured, a masking technique was devised so that a number of different peening operations could be carried out on one specimen.

Also, to ensure that the surface hardness of the bars manufactured was of the expected level, some tests have been carried out. The hardness measured on each face of the specimen varied from 54 to 57HRC. Knowing that the shot (Steel Shot $\mathrm{S} 230,0.6 \mathrm{~mm}$ ) used for this investigation had an approximate hardness of 55 to $65 \mathrm{HRC}$, which is harder than the specimen, it was expected to observe some effect from the shot peening process.

\section{Design of the Experimental Procedures}

As this investigation had a broad spectrum of possibilities, designing the experiments was a necessary step in order to focus on the relevant information and establish the effects and significance of the process from a practical point of view.

Six parameters and their significance were investigated, aiming at relating their conjugate effects to the residual stress introduced. Each parameter was tested at three different levels (Low, Medium and/or High).

In the following table, the list of control variables is shown, with their respective experiment levels and assigned values:

Table 1: The control variables and testing levels

\begin{tabular}{|c|c|c|c|c|}
\hline \multirow[b]{2}{*}{ Parameters } & \multirow[b]{2}{*}{ Low } & \multicolumn{2}{|c|}{ Testing levels } & \\
\hline & & Medium & High & \\
\hline Exposure Time (s) & -1 & & +1 & (2 Levels) \\
\hline Nozzle diameter (in) & -1 & & +1 & (2 Levels) \\
\hline Air pressure (bars) & -1 & 0 & +1 & (3 Levels) \\
\hline Distance nozzle-specimen (mm) & -1 & 0 & +1 & (3 Levels) \\
\hline Impact angle (deg) & -1 & 0 & +1 & (3 Levels) \\
\hline Mass flow adjustment $(\mathrm{kg} / \mathrm{min})$ & -1 & 0 & +1 & (3 Levels) \\
\hline
\end{tabular}

108 different set-ups were randomly allocated on the selected specimen, making sure that some sites were kept blank. The total number of experimental sites was 132 .

Each experimental site was processed with the required conditions and X-ray measurements were carried out to determine the residual stress profile introduced by the process. Figure 3 is a typical example of the profiles obtained: 


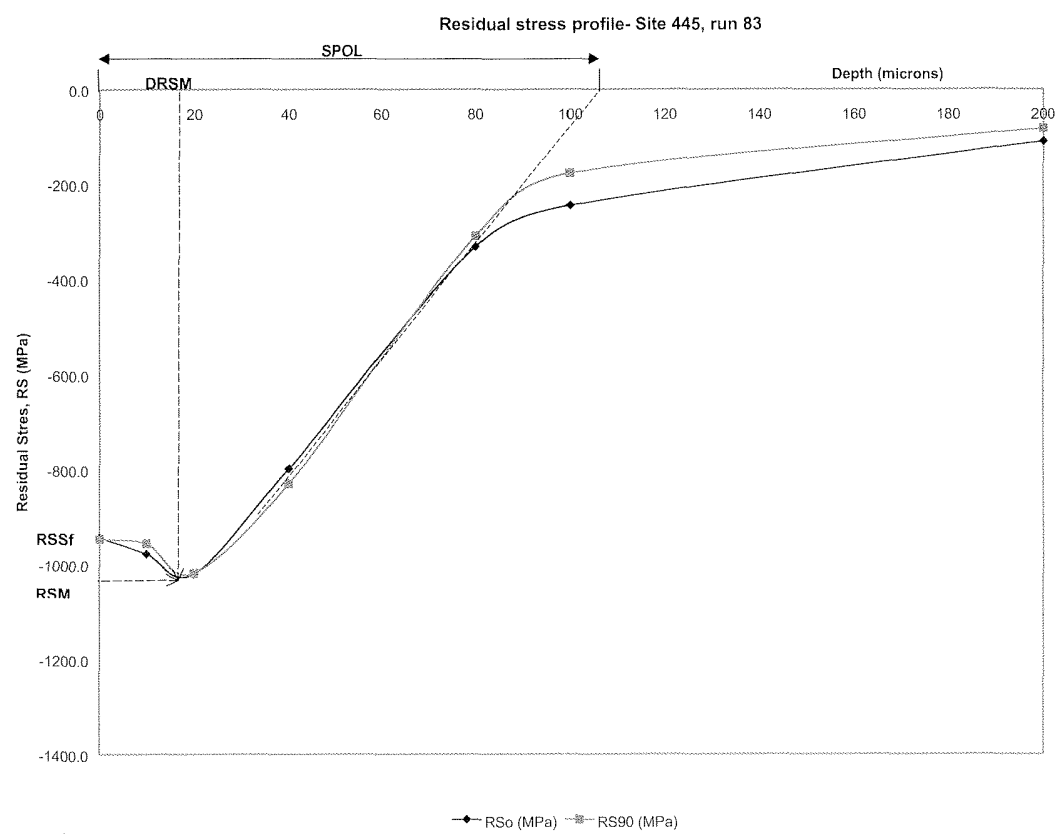

Figure 2: A residual stress profile obtained for one site for the main experimental program (e.g. RSM=1042.0MPa, DRSM=17.5 $\mu \mathrm{m}, \mathrm{SPOL}=105.0 \mu \mathrm{m}$ and $\mathrm{RSSF}=-944.5 \mathrm{MPa})$

The profiles obtained were then analyzed and key values recorded. The key values were:

- The maximum compressive residual stress (RSM, in MPa);

- The depth at which the maximum compressive residual stress occurs (DRSM, in $\mu \mathrm{m}$ );

- The depth of shot peened outer layer (SPOL, in $\mu \mathrm{m}$ );

- The surface residual stress before peening (measured on the blank experimental sites; RSSi, in $\mathrm{MPa}$;

- $\quad$ The surface residual after peening (RSSf, in MPa).

These key values were selected as being the most important final results. They will be used as the responses to be explained in terms of the 6 process parameters: their 6 main effects, the 4 quadratic effects and the 15 interactions using regression analysis.

\section{Statistical Treatment: Evaluation of the Significance of the Process Parameters and Interactions}

To carry out the statistical analysis, five responses were investigated in the statistical analysis:

- The maximum residual stress; (RSM, in MPa);

- The depth of the maximum residual stress (DRSM, in $\mu \mathrm{m}$ ); 
- The shot peened outer layer (SPOL, in $\mu \mathrm{m})$;

- The surface residual stress after peening (RSSf, in MPa);

- The variation in the surface residual stress from un-peened to peened ([RSSf-RSSi], in $\mathrm{MPa}$ ).

These results have been selected for various reasons. However, as it is intended to predict the residual stress distribution caused by the process, if RSM, DRSM, RSSf and SPOL are known it is then possible to define and "visualize" the residual stress profile.

The last result selected ([RSSf-RSSi]) for the analysis is not considered as a very important one. However, this value can be used as an indicator, showing the change in the residual stress at the surface due to the shot peening process.

\subsection{The Statistical Models}

The response variables in the regression were selected from the 6 main effects $(a, b, c, d, e$ and $f)^{1}, 15$ interactions $(a b, a c, a d, \ldots, e f)$ and 4 quadratic effects or squared terms $\left(c^{2}, d^{2}, e^{2}\right.$ and $\left.f^{2}\right)$. Two variables, $a$ and $b$, which were only at two levels $(-1$ and +1$)$, their squared terms $a^{2}$ and $b^{2}$ cannot be included for the analysis. Therefore, they do not appear in any of the equations found.

The process parameters effects were included in the final models if they were of obvious physical importance, or if they were statistically significant at the $10 \%$ level (p-value $<0.10$ ). In addition, the main effects were always included if the process parameter appeared in a significant interaction or quadratic term.

Observing and comparing the different stress profiles, differences can be seen, clearly showing the different influence from one set of parameters to another (Figure 3).

Looking at the residual stress maximum values (RSM), it was observed that the values ranged from $-600 \mathrm{Mpa}$ to $-1400 \mathrm{Mpa}$, with the majority of experimental sites exhibiting a maximum compressive residual stress ranging between -1000 MPa and $-1300 \mathrm{MPa}$ (Figure 4).

The corresponding depth (DRSM) varies from $0 \mu \mathrm{m}$ up $80 \mu \mathrm{m}$ (Figure 4), whilst the shot peened outer layer (SPOL), can be seen to range from $60 \mu \mathrm{m}$ to $390 \mu \mathrm{m}$ (Figure 5).

It can also be observed that a majority of experimental sites exhibit a maximum depth of residual stress of $10 \mu \mathrm{m}$ to $40 \mu \mathrm{m}$ and that the maximum shot peened outer layer varied between $80 \mu \mathrm{m}$ to $280 \mu \mathrm{m}$. Figure 5 also shows that the residual stress at the surface (RSSf) ranged from $650 \mathrm{MPa}$ to $-1080 \mathrm{MPa}$, with the majority of samples varying from around $-800 \mathrm{MPa}$ to -1000 $\mathrm{MPa}$.

These four responses are the most important. Indeed, a high compressive residual stress introduced deep in a component will help prevent crack initiation as well as enhancing the overhaul life expectancy of the processed part.

Looking at these results, it was also interesting to check if any correlation exists between these individual responses. The next graph (Figure 6) shows a plot of the depth DRSM as a function of the residual stress RSM. From this plot, it is possible to observe that when the maximum compressive residual stress RSM increases (in the negative direction), the depth of this residual stress tends to increase.

1. $a$ : Exposure time; $b$ : Nozzle size; $c$ : Air pressure; $d$ : Distance nozzle-specimen; $e$ : Impact Angle; $f$ : Mass Flow 

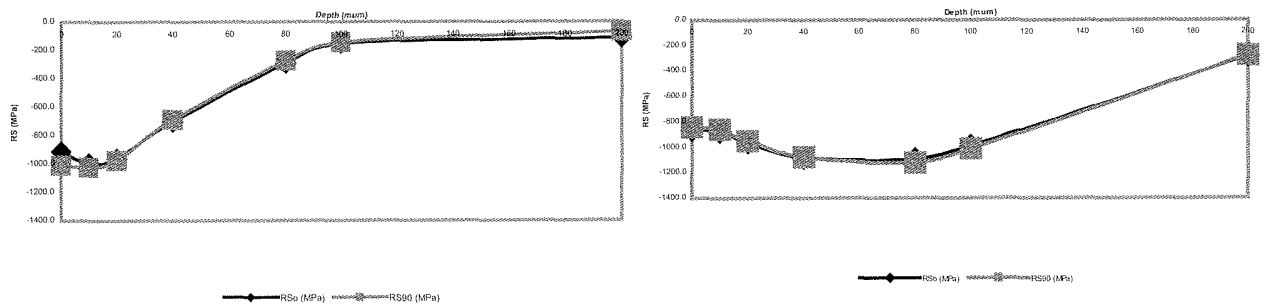

Figure 3: Residual stress profiles for 2 distinctive sets of parameters
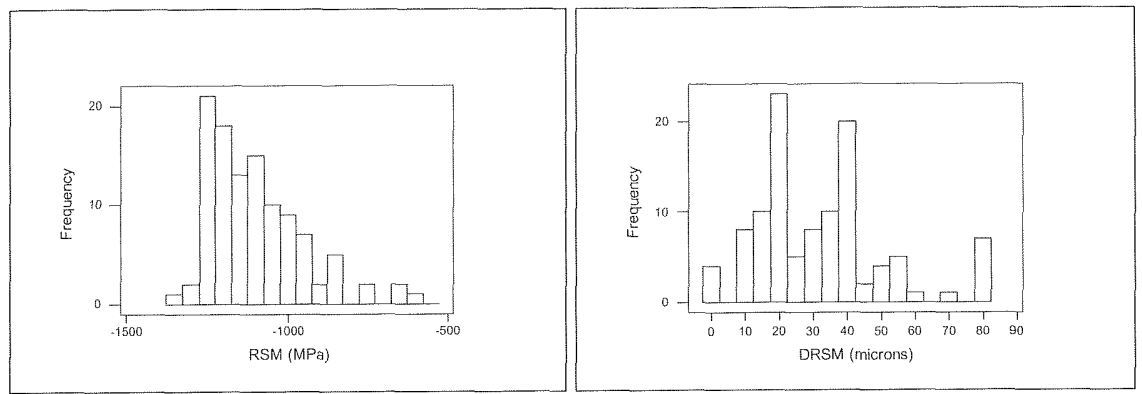

Figure 4: Repartition of the values obtained for RSM and DRSM over the experimental sites
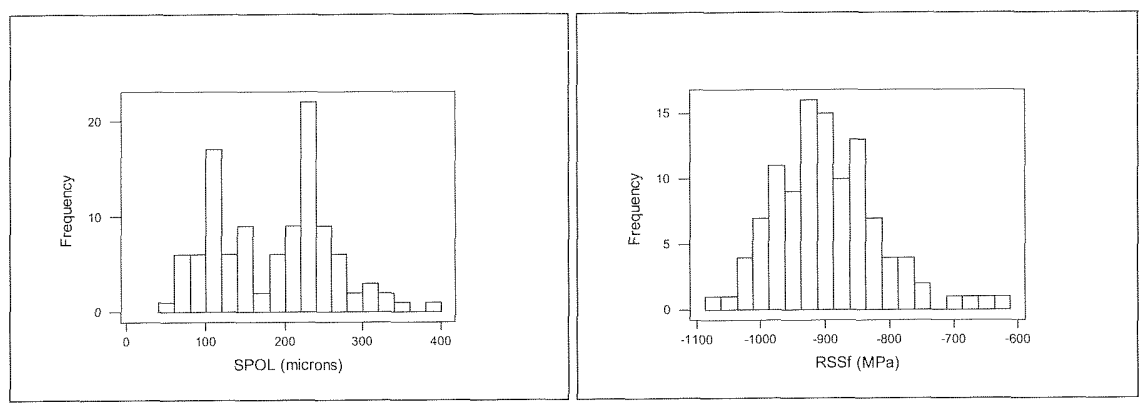

Figure 5: Repartition of the values obtained for SPOL and RSSf over the experimental sites

The $p$-value $(p$-value $=0.000)$ shows that this sample correlation is most unlikely to have occurred by chance if the variables RSM and DRSM are independent.

Carrying out the same analysis between RSM and SPOL we obtain the plot shown in Figure 6. It can be seen that, as above, an increase of RSM leads to and an increase of SPOL.

From the previous results and carrying out a similar analysis between DRSM and SPOL, the following graph was obtained (Figure 7). It is possible to see that as DRSM increases SPOL increases. 


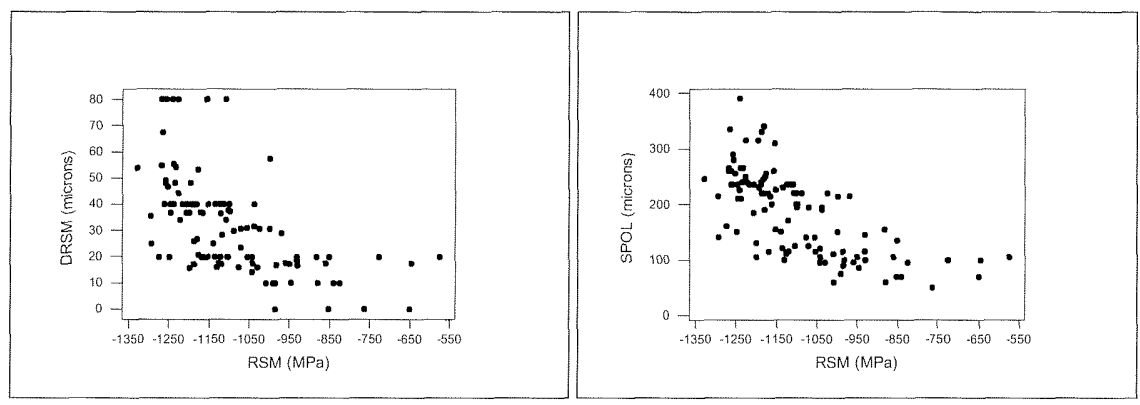

Figure 6: Correlation between RSM and DRSM (e.g. correlation of RSM and DRSM $=-0.588, P$-value $=0.000$ ) and correlation between RSM and SPOL (e.g. correlation of RSM and SPOL $=-0.683, P$-value $=0.000$ )

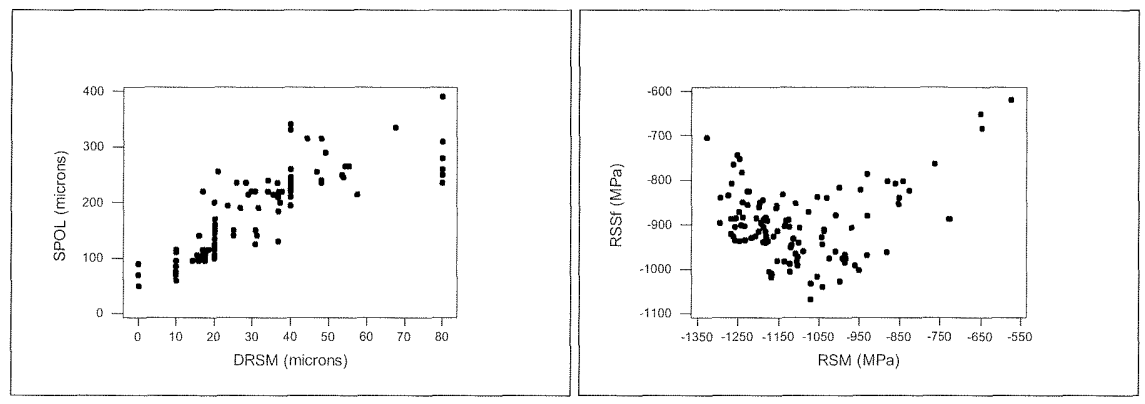

Figure 7: Correlation between DRSM and SPOL (e.g. correlation of DRSM and SPOL $=0.820, \mathrm{P}$-value $=0.000$ ) and correlation between RSM and RSSf (e.g. correlation of RSM and RSSf $=0.214$, P-value $=0.026$ )

The plot also shows that there are no obvious correlation between RSM and RSSf.

The correlations are desirable in as much as the high compressive residual stress is associated with an enhanced life expectancy of a component (e.g. a gear).

The final statistical models established for each response were as follows:

$$
\begin{aligned}
\operatorname{RSM}(\mathrm{MPa})= & -1158-58.6 a+9.94 b-118 c-58.3 e+ \\
& +10.2 f+88.8 c 2+17.5 a c+26.3 b f
\end{aligned}
$$

$$
\begin{aligned}
\operatorname{DRSM}(\text { microns })= & 35.8+3.11 a+15.3 c-2.14 d+6.46 e-5.58 f \\
& -5.34 e 2+3.83 a c+4.33 c e-2.53 d e
\end{aligned}
$$

SPOL (microns) $=199+2.18 a+65.0 c+35.0 e$

$$
-19.6 f-20.2 e 2-9.79 a e+12.3 c e
$$

$$
\begin{aligned}
\operatorname{RSSf}(\mathrm{MPa})= & -906+5.93 a-1.01 b+6.54 c+5.97 e+ \\
& +45.9 c 2-33.2 e 2+35.9 a c-14.5 b c
\end{aligned}
$$


$[$ RSSf- RSSi] $(\mathrm{MPa})=-744-37.1 b+41.4 c-77.8 d-51.8 b c+44.7 b d$

Considering the previous equation for RSM (Eq. 1). The objective is to optimize the values for $a, b, c, e$ and $f$, assuming that we want to minimize the value RSM (we want the most negative value).

The most negative value for RSM with the process parameters within the ranges investigated in the experiment is obtained when:

- $a=+1$;

- $b=+1$ :

- $c=+0.57$

- $d=-1$ :

- $e=+1$;

- $f=-1$.

Substituting these values into the equation (Eq. 1) leads to the following results:

Table 2: Optimum parameters and results

\begin{tabular}{l|llll}
\hline Parameters & Results & & $95 \% \mathrm{CI}^{*}$ & $95 \% \mathrm{PI}^{* * *}$ \\
\hline Exposure time $(a)=+1(3 \mathrm{~s})$ & RSM & $-1330 \mathrm{MPa}$ & $(-1375 ;-1285) \mathrm{MPa}$ & $(-1485 ;-1175) \mathrm{MPa}$ \\
Nozzle size $(b)=+1(5 / 16 ")$ & DRSM & $64 \mu \mathrm{m}$ & $(55 ; 70) \mu \mathrm{m}$ & $(40 ; 90) \mu \mathrm{m}$ \\
Air pressure $(c)=+0.57$ & SPOL & $270 \mu \mathrm{m}$ & $(250 ; 295) \mu \mathrm{m}$ & $(185 ; 355) \mu \mathrm{m}$ \\
$\begin{array}{l}(3.4 \text { bar }) \\
\text { Distance }(d)=-1(100 \mathrm{~mm})\end{array}$ & RSSf & $-900 \mathrm{MPa}$ & $(-930 ;-860) \mathrm{MPa}$ & $(-1050 ;-750) \mathrm{MPa}$ \\
Impact angle $(e)=+1(90 \mathrm{deg})$ & {$[\mathrm{RSSf}-$} & $-820 \mathrm{MPa}$ & $(-860 ;-650) \mathrm{MPa}$ & $(-1200 ;-300) \mathrm{MPa}$ \\
Mass flow $(f)=-1(1 \mathrm{~kg} / \mathrm{min})$ & RSSi] & & & \\
\hline
\end{tabular}

* $95 \% \mathrm{CI}$ is an interval of the average response if the process is operated with these parameter values.

** $95 \%$ PI is an interval within which there is $95 \%$ chance that an individual test could lie, assuming a Weibull distribution. In this case, the interval is equal to $\pm 3.7 * s$ (where $s$ is the standard deviation).

Using these results, we can determine what the optimum residual stress profile created would be (Figure 8).

This model is a prediction of what may happen if we carry out an experiment using the optimum parameters determined above. Ideally we would expect to achieve similar RSM, DRSM, SPOL and RSSf. The difference [RSSf-RSSi] is not critical in the sense that it relies on the "state" of the work piece prior to the process (how it has been manufactured and how well the different treatments such as grinding and/or heat treatment have been performed). 


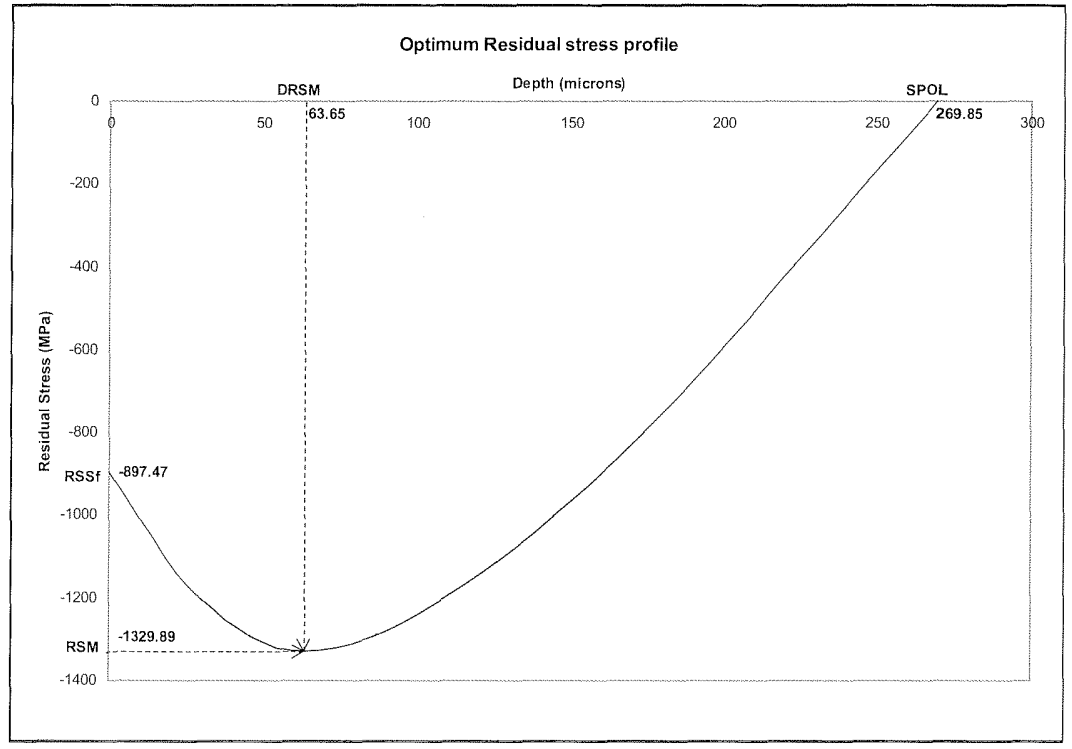

Figure 8: Optimum residual stress profile

\section{Conclusions}

The aim of this programme was to collect as much data as possible in order to carry out a full statistical analysis. As presented in the previous chapter, this statistical analysis led to several models corresponding to the five types of results felt to be most important in terms of the final material condition (RSM, DRSM, SPOL, RSSf and [RSSf-RSSi]).

By using these relationships between the selected results and the process parameters, optimum values were calculated to achieve the optimum final results required. This was based on the following requirements

- A high compressive residual stress (RSM);

- The greatest value for the depth of the maximum compressive residual (DRSM);

- The deepest shot peened outer layer (SPOL);

- A high compressive residual stress at the surface (RSSf);

The difference [RSSf-RSSi] was not considered so important (RSSf was more important than the level of change), although it was a good indication of the effect of the process on a component. The greatest this difference is, the better. 


\section{References}

[1] E. B. CHEE, Effect of Peening and Re-peening on the Improvement of Fatigue Life of InService Components, Cranfield University, 1982

[2] D. KIRK, Shot Peening, Seminar, USF Vacublast Slough, 1998

[3] METAL IMPROVEMENT COMPANY, Shot Peening Applications, $7^{\text {th }}$ Ed., USA, 1980>

[4] W. CAO, R. FATHALLAH, L. CASTEX, Correlation of AImen arc height with residual stresses in shot peening process, Materials Science and Technology, Sept. 1995, Vol. 11, pp. 967-973

[5] T. SENO, H. HORIUCHI, T. NAITO, Effect of various peening parameters on compressive residual stress for carburized steel, ICSP-3 Proceedings, pp. 505--512

[6] K. TOSHA, K. IIDA, Residual stress and hardness distributions induced by shot peening, Meiji University, ICSP-4 Proceedings, pp. 379-388

[7] R. FATHALLAH, G. INGLEBERT, L. CASTEX, Prediction of plastic deformation and residual stresses induced in metallic parts by shot peening, Materials Science and Technology, July. 1998, Vol. 14, pp. 631-639

[8] R. HERZOG, W. ZINN, B. SCHOLTES, H. WOHLFAHRT, The significance of Almen intensity for the generation of shot peening residual stresses, ICSP-6 Proceedings, pp. $270-280$

[9] M. OSHAWA, T. YONEMURA, Improvement of hardened surface by shot peening, Journal of the Japan Society for Heat Treatment, 1989

[10] M. HASHIMOTO, M. SHIRATORI, S. NAGASHIMA, The effects of shot peening on residual stresses and fatigue strength of carburized gear steels, ICSP-2 Proceedings, pp. 495-504

[11] A. NAKONIECZNY, W. SZYRLE, Residual stress, microstructure and fatigue behaviour of carburized layers before and after shot peening, ICSP-6 Proceedings, pp. 263-269

[12] M. HASHIMOTO, S. HOYASHITA, Improvement of surface durability of case carburized and hardened gear by shot peening and barreling processes, ICSP-6 Proceedings, pp. 34-43

[13] K. NAITO, T. OCHI, N. SUZUKI, Effect of shot peening on the fatigue strength of carburized steels, ICSP-4 Proceedings, pp. 519-526

[14] K. OGAWA, H. YAMADA, K. SAKURI, Influence of residual stress on fatigue strength of carburized and shot peened notched specimens, ICSP-4 Proceedings, pp. 445-454

[15] S. ADACHI, Fatigue strength of gear steels shot peened in extremely high intensity conditions, ICSP-4 Proceedings, pp. 363-372

[16] M. WIDMARK, A. MELANDER, Effect of material, heat treatment, grinding and shot peening on contact fatigue life of carburized steels, International Journal of Fatigue, 1999 , Vol. 21, pp. 309-327

[17] A. M. KORSUNSKY, An analysis of residual stresses and strains in shot peening, ICRS-5 Proceedings, 1999

[18] H. AOKI, E. NAGASHIMA, T. MIURA, Effect of shot peening conditions on fatigue strength of carburized steels, ICSP-4 Proceedings, pp. 513-518 